\title{
The Affective Dimensions of Mathematical Difficulties in Schoolchildren
}

\author{
Morena Lebens, Martin Graff, and Peter Mayer \\ Department of Psychology, Education and Careers, University of Glamorgan, Pontypridd CF37 1DL, UK \\ Correspondence should be addressed to Morena Lebens, mlebens@glam.ac.uk
}

Received 18 August 2010; Accepted 19 October 2010

Academic Editor: Eric Z. F. Liu

Copyright (C) 2011 Morena Lebens et al. This is an open access article distributed under the Creative Commons Attribution License, which permits unrestricted use, distribution, and reproduction in any medium, provided the original work is properly cited.

\begin{abstract}
Mathematical difficulties (MDs) are frequently characterised by cognitive deficits such as ineffective problem solving strategies and a lack of computational fluency. The established literature indicates that mathematical achievement is not only a function of cognitive factors but it also points to the importance of affective factors for the development of mathematical achievement. In the light of this evidence, the exploration of children's affective responses towards mathematics becomes a central issue. Whereas previous studies tended to research affective motivational constructs such as self-efficacy in isolation from other related constructs, the literature suffers from a shortage of research on the relationship between different affective motivational variables and their impact on mathematical achievement in different age and achievement bands. The present paper aims to address this aim by employing a newly developed instrument to measure affective motivational variables. Overall, the present findings support the assumption that children of average ability are less influenced by affective factors than children with mathematical difficulties.
\end{abstract}

\section{Introduction}

Affective factors in the mathematical sphere refer to "children's feeling about mathematics, aspects of the classroom such as teacher-student relationships, or their perception of themselves as learners of mathematics" (Reyes [1]). This definition of affective responses constitutes the operational foundation of the instrument employed for the purpose of the present study. A review of previous research indicated that mathematical achievement is related to a variety of affective variables such as maths anxiety (Ashcraft \& Kirk [2]; Ma [3]; Kellogg et al. [4]; Grootenboer and Hemmings [5], Rubinsten \& Tannock [6], Hemmings et al. [7]), children's perceptions of the maths teacher, (Goh and Fraser [8]; Wentzel [9]), children's self-efficacy beliefs (Marsh [10]; Bandura [11]; Marsh and Craven [12]; Chiu \& Whitebread [13]), and their perception of the classroom environment during maths lessons (Kellam, Brown, Poduska, et al., 1998). However, it is argued that the complex nature of affective responses is not fully reflected in the extant literature, because existing instruments are primarily focussed on measuring intraindividual factors such as mathematics anxiety (Wigfield \& Meece [14]) and self-efficacy. This seems to reflect the unarticulated assumption that affective responses towards mathematics can be explained in terms of intraindividual processes. Interindividual aspects such as classroom environment and teacher-student rapport have not been fully discussed in the literature so far. Therefore, the paper is intended to provide a more comprehensive analysis of affective responses, which go beyond an examination of self-efficacy and maths anxiety. Nevertheless, the paper does not attempt to cover the entire set of affective variables. Rather, this paper seeks to address a set of selected factors which have been identified as considerable aspects of mathematical achievement. The rationale of the present paper is to extend the previous literature by examining the intraindividual and interindividual facets of affective responses towards mathematics in children with mathematical difficulties and normally achieving children. The following sections provide a condensed review of the literature on the abovementioned phenomena.

According to Bandura [15], self-efficacy is defined as "individuals' judgements of how well one can execute 
courses of action required to deal with prospective situations... people's judgements of their capabilities influence their thought patterns and emotional reactions during anticipatory and actual transactions with the environment." Maths self-efficacy has been defined as "individuals' judgements of their capabilities to solve specific math problems, perform math-related tasks, or succeed in math-related courses" (Betz \& Hacket [16]). There is compelling evidence that self-efficacy exerts a greater influence on maths achievement than mental ability (Pajares and Kranzler [17]). This supports Bandura's assertion that self-efficacy beliefs influence effort expended and persistence and therefore mediate the effect of skill and ability on achievement outcomes. Pajares and Miller [18] employed the path analysis technique in order to investigate the predictive utility of self-efficacy for students' problem solving performance and the role of self-efficacy beliefs in mediating self-concept and anxiety. Self-efficacy beliefs were measured by the Mathematics Confidence Scale (MCS), which is specifically targeted towards college students with respect to the types of tasks. The scale asks participants to judge their ability to solve a given mathematical problem correctly. The problems differ with respect to the area of mathematics they cover (arithmetic, algebra, geometry), cognitive demands (computation, comprehension and application), and problem context (real and abstract).

Maths anxiety was measured by the Mathematics Anxiety Scale, consisting of ten items. The instrument that has been employed for measuring self-concept is an adapted version of the Self Description Questionnaires. Problem-solving performance was measured by an eighteen item, multiple choice instruments which is specifically targeted towards college students. The results of the path analysis indicated that selfefficacy was more predictive for performance than the selfconcept measure, maths anxiety, and previous experiences. Pajares and Kranzler [17] extended the previous study by including the psychometric measure $g$ as a measure of general mental ability in their path analysis and showed that self-efficacy had a strong effect on both maths anxiety and problem-solving performance, even with a control in place for general mental ability. Also, self-efficacy was found to be partially responsible for the effects of $g$ and maths background on maths anxiety and problem solving performance. Thus, the findings strengthen Bandura's assertion that selfefficacy is a fundamental variable for academic achievement outcomes.

A more recent meta-analysis on the relationship between mathematics anxiety and achievement is provided by $\mathrm{Ma}$ [19]. The meta-analysis was based on a sample of 26 studies, which included eighteen peer-reviewed articles, three unpublished articles and five dissertations. The analysis showed a correlation coefficient of -.27 for the relationship between maths anxiety and achievements, which corroborates the results of Hembree [20]. The results led to the conclusion that towards the end of primary school (age 10-11), onwards, there is a significant relationship between achievement and anxiety. There was no significant variation in the relationship between mathematics achievement and anxiety from classes four to nine.
However, Ma examined the development of maths anxiety over time by aggregating class levels to compare maths anxiety and achievement from classes four to six, seven to nine, and ten to twelve, rather than examining the change and stability of the maths anxiety and achievement on a year-by-year basis. It was found that there was no difference in the relationship between achievement and anxiety in classes four and six, classes seven and nine, and classes ten and twelve. It remains open to scrutiny whether there is a difference when comparing classes four and ten, for example, which are characterised by different demands and classroom environments. Separate comparisons between each class level would have been more informative than the aggregation of data.

Also, it should be noted that the majority of studies in Ma's meta-analysis used a standardised test to measure maths anxiety. It is possible that children who suffer a high level of anxiety are at a disadvantage in test situations because the presence of mathematical stimuli elicits their anxiety, which in turn might constitute a serious impediment to their test performance. Therefore, the test scores of anxious children might not be indicative of their achievement because they may be affected by their level of anxiety (Kellogg et al. [4]). A possible resolution would be to include studies which operationalise maths achievement in terms of teachers' mathematic grades rather than single test scores, since teachers' grades might provide a more realistic depiction of children's verbal and written achievement in the everyday classroom environment over a longer period of time.

Although the causal ordering of math anxiety and low achievement remains essentially ambiguous (Newstead [21]), empirical findings indicate that the learning environment is a considerable risk factor for maths anxiety. Indeed, Ashcraft and Krause (2007) predict that "math anxiety is learned in the classroom in front of the teacher and his or her peers. In short, lower than average math abilities and/or working memory capacity, susceptibility to public embarrassment and an unsupportive teacher all may be risk factors for developing math anxiety." To sum up the findings reviewed so far, there seems to be substantial evidence for a negative relationship between maths anxiety and achievement which is perpetuated through factors such as the learning environment. Children's individual differences in attitudes towards their teacher are linked to differences in achievement. More specifically, attitudes towards the teacher's teaching style, interpersonal behaviour, and supportiveness influence children's achievement-related beliefs and actual achievement. This issue has been addressed in a study by Goh and Fraser [8].

Using an adapted version of the Questionnaire on Teacher Interaction (QTI), Goh and Fraser [8] examined children's perceptions of their teacher's interpersonal behaviour and its association with cognitive outcomes. Their sample consisted of a total of 1,512 children aged between ten and eleven. In its original format, the QTI consisted of 64 items. Several adaptations have been developed such as a shorter version which is targeted towards primary school children and which has been used by Goh and Fraser [8]. Cognitive performance was measured by a ten item 
mathematics achievement test. The results of a hierarchical linear model analysis suggest that successful mathematics achievement could be predicted by particular types of teacher behaviour such as leadership, understanding, and helpfulness. As summarised by Goh and Fraser [8] "better achievement was found in classes with an emphasis on more teacher Leadership, Helping/Friendly and Understanding behaviours."

Murdock and Miller [22] examined the relationship between perceptions of the teacher and achievement motivation. Their sample consisted of 206 children from class eight. Motivation was assessed through three measures: self-reports of efficacy, self-reports of children's valuation of learning and teacher's report of children's effort. In addition, the researchers controlled for children's perceived motivational impact of parents and peers. The results of a regression analysis indicated that children's perception of the teacher accounted for a considerable amount of the variance in all of the three measures of motivation, when peer and parental influences were held constant. This implies that a positive perception of the teacher can increase children's motivation and this, in turn, is related to an increase in achievement (Wentzel [9]).

Midgley et al. [23] investigated how children's perceptions of their teacher changed as a function of the transition from primary to secondary school and how these changes are related to changes in their perceived value of mathematics. A total of 2,501 children took part in the study. Based on performance in a standardised test of mathematical ability, children were grouped either as high achievers or children with MD. Children's valuation of mathematics was measured by two scales, each consisting of four items. Children's perception of the teacher was measured by a subscale, consisting of six items, from an instrument which assesses children's perception of the classroom environment. The data were collected before and after transition to secondary school, over a period of two years. A two-way analysis of variance showed that children who moved from supportive teachers to less supportive teachers after the transition to secondary school experienced decline in their interest in mathematics. Given that the perceived value of mathematics is an important factor for mathematical motivation and achievement, it can be concluded that children's perceptions of their teacher plays a considerable role in the learning of mathematics.

Another finding in the Midgley et al. [23] study was that the decline in the perceived value of mathematics when moving to a less supportive teacher after transition from primary to secondary school was more pronounced for low achieving than for high achieving children. This implies that low achieving children are more affected by their perceptions of the mathematics teacher and the present study attempts to investigate this issue further. To date, there is no research on how the relationship between individual achievement and children's perceptions of their teacher develop in children with MD and average ability children.

The interaction with others in a microsystem such as the classroom plays a critical role in children's cognitive development. Peers in the classroom, for example, serve as a model for behaviour and therefore influence children's own perception of classroom conduct and adaptive behaviour. As children move into adolescence, the influence of peers on children's academic achievement is more powerful than the influence of their parents (Steinberg [24]). Indeed, Barth et al. [25] argue that adaptive behaviours, for example, task orientation and prosocial interactions, are facilitated in classrooms which consist mainly of children who exhibit these behaviours and provide role models for others. Overall, the children's perception of their classroom environment is an important variable for mathematical achievement. As argued by Barth et al. [25], children's behaviour in the classroom is influenced by the behaviour of their peers: "classrooms which are mainly populated by children who exhibit deviant behaviour and misconduct are likely to perpetuate these maladaptive behaviours" (Barth et al. [25]). However, the majority of studies seem to have been conducted with average achieving children, and not on perceived learning environment in children with and without academic difficulties, who are tracked in different schools and therefore experience distinctive classroom environments.

The objective of this paper is to account for the role of affective responses through an investigation of the affective profiles in children with mathematical difficulties and average achieving children. The instrument employed for the purpose of the present study is comprised of four subscales to measure different affective variables in mathematical contexts. The examination of children from class 5 (first class of secondary schooling) and class 8 is intended to provide preliminary insights into the developmental trajectories of affective responses towards mathematics.

\section{Method}

2.1. Participants. In total 143 children took part in this study, 91 children with $\mathrm{MD}$ and 52 children from an average achieving control group. The participants were drawn from two class groups, years 5 and 8 . From year 5 , there were 46 children with mathematical difficulty, (mean age $=11.5 ; 19$ males and 23 females), and 29 average achieving children from year 5 (mean age $=11.2 ; 16$ males and 13 females). From year 8 , there were 45 children with mathematical difficulties (mean age $=14.2 ; 26$ males and 19 females), and 23 average achieving children from year 8 (mean age $=13.7$; 13 males and 10 females).

Children were classified as having mathematical difficulties on the basis of two criteria (in order to comprehend the criteria, it is important to note that the grade system in Germany ranges from 1 (very good) to 6 (fail) and schoolchildren are tracked on different secondary school types depending on their ability in primary school). Children with MD were children from a general secondary school (Hauptschule), whereas normally achieving children were recruited from a comprehensive school. It is important to mention that children in Germany are segregated into different school types on the basis of their overall school achievement in primary school. The extent to which achievement corresponds to children's actual ability is not established. 
Table 1: Attitudes towards the teacher.

\begin{tabular}{lccc}
\hline \multicolumn{4}{c}{ Cronbach's alpha: .83 } \\
\hline Item & Loading & $\begin{array}{l}\text { Item-Total } \\
\text { Correlation }\end{array}$ & $\begin{array}{l}\text { Scale if item } \\
\text { deleted }\end{array}$ \\
\hline $\begin{array}{l}\text { My teacher } \\
\text { approaches all } \\
\text { children equally }\end{array}$ & .62 & .60 & .83 \\
\hline $\begin{array}{l}\text { I enjoy the math } \\
\text { lessons with my } \\
\text { teacher }\end{array}$ & .70 & .59 & .83 \\
\hline
\end{tabular}

In addition to school segregation, children were identified as having mathematical difficulties if their school grade in mathematics was "4" or lower, because within the range of school grades from 1 (very good) to 6 (inadequate), the grade 4 refers to a dissatisfying achievement. The two schools selected for the research were chosen because their student population was comparable with respect to socioeconomic background. The information of the demographic composition of the student population has been derived from published data from a large-scale educational assessment which included measures on the demographic characteristics of the catchment area.

2.2. Materials/Apparatus. The maths affective dimension scale (MADS), which was employed for the present study consisted of four subscales and a total of 16 items. The four subscales measured the factors math anxiety, attitudes towards the teacher, self-efficacy beliefs and perceived learning environment. The preliminary pool of items has been derived from the literature which shows how the learning of mathematics in school is related to different affective variables such as math anxiety, the perceived quality of teacher-student interaction, the extent to which children like cooperative learning activities, children's attribution of success or failure in mathematics, and their perception of the classroom climate in maths lessons. The literature that has been reviewed implies that measures of affective responses towards maths need to unpack the concepts of learning mathematics in school in order to account for the diverse aspects which are included in the subject of mathematics, as outlined below. Therefore, the items for the present instrument were developed to measure the affective responses towards the different aspects of mathematics. Example items from each scale are provided in Tables 1, 2, 3 , and 4 .

2.3. Procedure. The assessment took part towards the end of the first semester, meaning that children from year five had sufficient experience with learning mathematics at a secondary school level to express their affective responses towards the different aspects of learning mathematics in classroom settings. On average, the questionnaire took 3035 minutes to complete. The association between children's affective responses and their individual performance was measured using the individual mathematics grades of children, as indicated on their school reports.
TABLE 2: Mathematics anxiety.

\begin{tabular}{lccl}
\hline \multicolumn{4}{c}{ Cronbach's alpha: .63 } \\
\hline Item & Loading & $\begin{array}{l}\text { Item-Total } \\
\text { Correlation }\end{array}$ & $\begin{array}{l}\text { Scale if item } \\
\text { deleted }\end{array}$ \\
\hline $\begin{array}{l}\text { I am afraid to } \\
\text { come up with a } \\
\text { wrong answer }\end{array}$ & .44 & .47 & .6 \\
\hline $\begin{array}{l}\text { I am afraid of } \\
\text { math } \\
\text { examinations }\end{array}$ & .42 & .53 & .57 \\
\hline
\end{tabular}

TABLE 3: Learning environment.

\begin{tabular}{lccl}
\hline \multicolumn{4}{c}{ Cronbach's alpha: .81 } \\
\hline Item & Loading & $\begin{array}{l}\text { Item-Total } \\
\text { Correlation }\end{array}$ & $\begin{array}{l}\text { Scale if item } \\
\text { deleted }\end{array}$ \\
\hline $\begin{array}{l}\text { My class fools } \\
\text { around during } \\
\text { math lessons }\end{array}$ & .63 & .65 & .77 \\
\hline $\begin{array}{l}\text { It takes long until } \\
\text { we can really start } \\
\text { with the lesson }\end{array}$ & .7 & .65 & .76 \\
\hline
\end{tabular}

TABLE 4: Self-efficacy.

\begin{tabular}{lccl}
\hline \multicolumn{4}{c}{ Cronbach's alpha: .68 } \\
\hline Item & Loading & $\begin{array}{l}\text { Item-Total } \\
\text { Correlation }\end{array}$ & $\begin{array}{l}\text { Scale if item } \\
\text { deleted }\end{array}$ \\
\hline $\begin{array}{l}\text { If I learn well, I } \\
\text { will have good } \\
\text { grades in maths }\end{array}$ & .5 & .43 & .55 \\
\hline $\begin{array}{l}\text { I simply have no } \\
\text { talent for maths }\end{array}$ & .5 & .58 & .43 \\
\hline
\end{tabular}

\section{Results and Discussion}

3.1. Scale Analysis. Initially a discriminatory item analysis was performed, items below a discriminatory threshold of 0.2 were rejected, to strengthen the internal consistency of the scale. Also, items with an insufficient item-total coefficient were eliminated in line with the psychometric recommendations of Loewenthal [26]. The results of the analysis of internal consistency show an overall Cronbach's alpha measure of 0.88 . The split half test resulted in a Spearman-Brown correlation coefficient of 0.83 . The Cronbach's alpha measure on the subscale level indicated an internal consistency for the math anxiety scale (0.63), the attitudes towards the teacher scale (0.83), the self-efficacy scale (0.68), and the learning environment scale (0.81). The repeated administration of the instrument after an interval of 3 weeks showed a retest reliability of $r_{\mathrm{tt}}=0.86(P=.01)$.

3.2. Math Anxiety. The results indicated that children with mathematical difficulties are more anxious about learning mathematics than their average ability peers. The results of the two-between factor ANOVA show that the main effect 
of achievement is statistically significant, $F_{(1,139)}=34.07$, $P<.05$. Further, the anxiety score of children with MD and average ability children differs across classes five and eight. This reflects the fact that there is a significant interaction effect between the two variables achievement and class, $F_{(1,139)}=7.92, P<.05$.

3.3. Linear Regression Analysis. A linear regression was carried out to examine the extent to which anxiety scores predict the individual performance of children with MD and average ability children, as determined by the mathematics grades on their school reports from winter 2007/2008. For children of average ability from class five, there is a relatively weak association between children's report grade and anxiety measure (multiple $R=.46$ ). It was found that for every increase on the anxiety measure by 1 , school report grades decline by .98 (roughly one grade unit). The anxiety measure accounts for 18\% (adjusted $r^{2}$ ) of the variability in the school report grade for mathematics. The $F$ value $\left(F_{(1,27)}=7.2\right)$ has an associated probability value of $P<.001$, which shows that this association is significant. For children with MD from class five, the association between the anxiety measure and school grade in mathematics is weak (Multiple $R=.34$ ) and not significant $\left(F_{(1,44)}=.51, P=.82\right)$.

The association between the anxiety measure and school grade for children of average ability from class eight is not statistically significant $\left(F_{(1,27)}=.72, P=.79\right)$. Thus, variability in mathematics grades predicted by anxiety measure among children of average ability is likely to be due to chance. This is different in the group of children with MD from class eight, where there is a moderate (multiple $R=.50$ ) association between anxiety measure and school grade. The anxiety measure predicts school grade in $24 \%$ of the cases (adjusted $r^{2}$ ), and this association has been found to be statistically significant $\left(F_{(1,43)}=14.49, P<.01\right)$. As the anxiety measure increases by 1 , school grades decline by 1.15 .

3.4. Discussion. The results of maths anxiety in children with MD produced an outcome which corroborates the findings of a great deal of the previous work in this field: the findings show that children with mathematical difficulties are significantly more anxious than children of average ability. The findings are in conjunction with the results of Hembree [20] and Ma [19]. However, the causal direction of mathematics achievement and anxiety remains ambiguous.

3.4.1. Developmental Trajectories of Maths Anxiety. In addition to the overall difference in anxiety between children with MD and average ability children, the results suggest that anxiety seems to develop differently between classes five and eight in children with MD and average ability children. There is a significant difference between children with MD from classes five and eight, in that children with MD are significantly more anxious than average ability children from class five. This suggests that anxiety increases from class five to eight in children with MD opposes the results of Hembree's meta-analysis [20] of 151 studies on mathematics anxiety, which showed that mathematics anxiety increases up to class nine or ten and then starts to decrease. Hembree's findings have been utilised to support the predictions of the deficit model, developed by Tobias [27]. In essence, this model assumes that mathematics anxiety is not the cause but the product of low achievement. However, contrary to Hembree's expectations, this study did not find a significant difference in anxiety between children of average ability from classes five and eight.

Furthermore, the prediction of the deficit model does not seem to be supported by the present finding that anxiety seems to increase only in children with MD, whereas anxiety in children of average ability remains constant. It could be argued that, if the increase in anxiety can be attributed to the frequency of failure and low achievement, as predicted by the deficit mode (Tobias, 1995; Ma \& Xu [3]), then there should also be an increase in anxiety between average ability children from classes five and eight, because even average ability children are likely to have experienced low achievement. Indeed, individual grades are normally distributed in both groups and therefore there are children with low grades, even among the group of children of average ability. However, the results show that this is not the case. Therefore, it seems that increasing maths anxiety is not solely related to individual achievement per se. One possible explanation for the increase of anxiety in children with MD from class five to eight is that the repeated experience of being categorised and stigmatised as a low achiever leads to a negative self-evaluation.

The finding that the effect of the role of anxiety on individual achievement decreases in children of average ability but increases in children with MD from class five to eight supports the hypothesis that anxiety is a function, not only of low achievement or failure, but of repeated negative experiences within a particular school environment. This follows the argument of Dossel [28], who criticises that attempts to establish a causal relationship between anxiety and achievement have been unsuccessful in the past "perhaps anxiety and achievement are caused by a different factorpossibly the learning/teaching environment." Indeed, Newstead [21] emphasizes that environmental factors have considerable impact on maths anxiety.

The results seem to indicate that the longer children attend a general secondary school which is almost exclusively populated by low achieving children with learning difficulties, the greater the likelihood that they have experienced failure and frustration which gives rise to feelings of tension and anxiety and leads to a vicious circle. The negative experiences might be due to the fact that, irrespective of the individual grades, children with MD are considered to be "children with MD" because they attend a certain school type and have very limited occupational chances. Thus, children with MD are more likely to experience negative responses from parents, the teacher and even their peers which, in turn, lead to negative self-evaluation and anxiety. This might form a vicious circle, because there is evidence that anxiety interferes with the cognitive processes required for mathematics and this interference affects children's performance (Ashcraft \& Kirk [2]). Such an explanation would be advocated by proponents of the interference model, which has been previously described. 
In sum, anxiety is predictive for the variance in achievement of children with MD from class eight, but not for children with MD from class five, which suggests that anxiety gradually increases over time. Contrary to expectations, this is the other way round for children of average ability, where anxiety is predictive for mathematics grades in class five but not in class eight. Despite this apparent inconsistent pattern of findings, these results add further support to the assumption of the interference hypothesis. According to Hunt [29], everyday learning activities in the mathematics classroom such as going to the chalkboard or being asked by the teacher to answer questions verbally can cause anxiety in children because they fear revealing their inability in front of their peers.

3.4.2. Conclusion. The finding that there were no significant differences in anxiety between children from classes 5 and 8 of an average ability cohort children, whereas there is a significant increase in anxiety between children from classes 5 and 8 points to a complex interplay between anxiety, achievement and the specific experiences children encounter in their particular school environment, which include the responses from significant others such as teachers, peers, and parents. This notion corresponds to the argument forwarded by $\mathrm{Ma}$ and $\mathrm{Xu}$ [3], namely, that anxiety is a function of the interaction of cognitive, personal, and environmental factors. Indeed, the strength of the relationship between maths anxiety and achievement becomes insignificant or is substantially reduced when controlling variables such as attitudes towards the teacher, attitudes towards the mathematics classroom environment, and children's perception of their abilities are introduced (Fennema \& Sherman [30]). An analysis of the measurement of self-efficacy and children's attitudes towards the teacher is therefore essential in order to discuss how these constructs are related to the measure of anxiety.

3.5. Attitudes towards the Teacher. Children of average ability have a mean score of 3.95 compared to an average of 3.16 in the group of children with MD. A two-between factor ANOVA shows that the main effect of achievement is statistically significant, $F_{(1,139)}=34.85, P<.01$. As with the anxiety subscale, the results of the ANOVA show that there is an interaction effect between achievement and class $F_{(1,139)}=8.24, P<.05$.

3.6. Linear Regression Analysis. For children of average ability from class five, there is a moderate association between children's school report grade and their attitudes towards the teacher (multiple $R=.5$ ). It was found that, if the measurement of attitudes towards the teacher increases by one unit, school report grades improve by .95 . This measure accounts for $27 \%$ (adjusted $r^{2}$ ) of the variability in school report grade for mathematics. The $F$ value $\left(F_{(1,27)}=\right.$ 11.1) has an associated probability value of $P<.05$, which shows that this association is significant. There is no significant association between the attitudes towards the teacher subscale and the school grades of children from class five with $\operatorname{MD}\left(F_{(1,44)}=1.33, P=.26\right)$.
For children of average ability from class eight, there is a low association between the measurement of children's attitudes towards the teacher and school grades (Multiple $r=.01)$, which is not statistically significant $\left(F_{(1,21)}=.004\right.$, $P=.95)$. In contrast, there is a moderate (multiple $r=.65$ ) and significant $\left(F_{(1,21)}=32.14 ; P<.1\right)$ association between the measurement of children's attitudes towards the teacher and the mathematics grades of children with MD from class eight: as the measurement of attitudes towards the teacher increases by one unit, school grades improve by 1.2. The affective responses of children with MD from class eight towards their teacher accounts for 41\% (adjusted $r$ ) of their individual mathematics grades.

3.7. Discussion. As has already been emphasized, attitudes towards the teacher are distinct from perceptions of the teacher. The rationale behind this decision is that the subscale contains items such as I enjoy mathematics with my teacher, which trap attitudes and therefore involve favourable or unfavourable evaluation, whereas other items such as "My teacher approaches all children equally" trap perceptions and beliefs, which merely represent an individual's information about the object (Fishbein \& Azjen [31]).

Overall, the findings show that attitudes towards the teacher are significantly affected by children's general achievement level: children with MD from classes five and eight respond more negatively towards their teacher than children of average ability. This finding indicates that children of average ability perceive their teacher as more helpful and supportive and they perceive the teaching style as more effective than their peers with MD. This corresponds to previous findings in the literature, which show that the perceived supportiveness of the teacher and the perceived quality of the teacher-student interaction emerged as reliable predictors of mathematical achievement (Dossey, 1992). In order to account for their difficulties, children with $\mathrm{MD}$ are tracked on general secondary schools, where behavioural peculiarities and a lack of classroom discipline are particularly prevalent. The finding that these children hold more negative attitudes towards the teacher imply that problematic behaviour and disobedience is related to lower levels of teacher support.

3.7.1. Developmental Trajectories of Attitudes towards the Teacher. The previous literature shows that children's attitudes towards the teacher deteriorate as they proceed through the secondary school years (Midgley et al. [23]). However, the present results provide only partial support for this notion; where the affective responses of children with MD actually appear to decrease over the years, the affective responses of children of average ability remain constant from class five to class eight. The finding that the decrease in affective responses over the years has only been observed for children with MD tentatively suggests that children's attitudes towards the teacher vary not only as a function of age, but also of achievement. Thus, it seems plausible that the attitudes towards the teacher develop differently across the secondary school years in children with MD and average 
ability children. This can be supported, to some extent, by the findings from the linear regression analyses, as will be discussed below.

According to the results of the linear regression analysis, the association between children's attitudes towards the teacher and their achievement is particularly pronounced in children of average ability from class five, where the attitudes towards the teacher account for $27 \%$ of the variance in individual mathematics grade. However, there is no significant association between attitudes towards the teacher and individual grades for children with MD from class five. This finding was unexpected, because it was anticipated that the achievement of children with MD would be more affected by their affective responses towards the teacher. Indeed, the results differ from some published studies (Kroesbergen et al. [32]; Mayer [33]), which suggest that the achievement of children with MD is more likely to be affected by teaching style and teacher support than the achievement of children of average ability. It seems possible, however, that the teacherstudent interaction differs between children with MD and average ability children and gives rise to different affective responses towards the teacher.

While there was no significant association between attitudes towards the teacher and individual grades for children with MD from class five, the result is different for children with MD from class eight where the response towards the teacher accounts for $41 \%$ of the variance in individual grade. One possible reason for this association might be that by class eight, children with MD might have developed their own explanatory model for academic success and failure, and they might be aware that the support of the teacher is crucial for academic success. The idea that children from class eight developed their own theories for success or failure, in which the teacher plays an important role, can be linked to the concept of self-efficacy, which refers to children's evaluation of their ability to attain a certain level of achievement (Bandura [34]).

3.7.2. Self-Efficacy and Attitudes towards the Teacher. Based on the present results, it seems plausible to assume that children with MD from class eight believe that their achievement is largely determined by their teacher and his or her support and teaching style rather than the outcome of their own actions. Indeed, previous studies have demonstrated that average achievers tend to explain success in terms of internal, stable factors such as effective learning which is linked to a positive feeling of self-efficacy, whereas children with MD tend to attribute academic success, not to internal factors, but to external factors such as the teacher's support and they believe that success or failure is determined by external factors that lie outside their scope of action (Bandura [11]). In other words, children with MD might simply withdraw when confronted with disappointing results and attribute their underachievement to the teacher whereas children of average ability might acknowledge that they should learn more.

This might also explain why children with MD from class eight hold significantly more negative attitudes towards the teacher than children with MD from class five. To recap, it might be the case that children with MD from class eight attribute academic success to external factors such as teaching style or the level of support they receive, which results in: (a) attitudes towards the teacher which are more negative than the responses of class five children and (b) the association between their attitudes towards the teacher and their individual grades.

The abovementioned hypothesis receives further support from the finding that the association between attitudes towards the teacher of children with MD from class eight, and their achievement is absent for children with MD from class five. Hence, it seems possible that the association between children's affective responses and their achievement in class eight is linked to their theories of success and failure, as well as their self-efficacy beliefs, because children's belief systems develop over time. In class five, children might not perceive their teacher as an important factor for academic success, presumably because they believe that success is the outcome of their own actions. However, over the secondary school grades, children with MD form their own theories for the reasons behind their low achievement, and this might result in the belief that academic success is largely determined by the teacher. This possibility is reversed for children of average ability, a group which is generally considered as average achieving, irrespective of their individual school grades. Whereas attitudes towards the teacher are predictive for individual grades in class five, such an association is absent in class eight, which suggests that children of average ability might begin secondary school with the assumption that their achievement can be attributed to the teacher, but then change this theory in class eight as a result of their experience of self-efficacy.

3.7.3. Teaching Style and Attitudes towards the Teacher. An additional reason why there is a strong association between attitudes towards the teacher and the individual grades of children with MD from class eight but not from children of average ability from class eight is that the learning process of children with MD is more likely to be affected by the way in which mathematics is explained to them (Carnine [35]). This supports a robust finding in the literature, namely, that children with MD need highly structured and explicit instruction (Bottge, 2001; Kroesbergen \& Van Luit, 2003; Kirschner et al. [36]; Graff, Lebens \& Mayer, 2007; Lebens [37]) while children of average ability are less dependent on the teacher because they are able to learn mathematical concepts and strategies through discovery and exploration. Children with MD need to have clear explanations and worked out examples for how to use the appropriate strategies in order to solve a problem.

Therefore, teaching style and format of instruction are key factors for the individual achievement of generally low achieving children. The reason why there is no association between attitudes towards the teacher and individual grades of children with MD from class five might be that the curriculum for class eight is far more complex than in class five, and the way in which mathematics is explained by the 
teacher might therefore be more important for older children with MD than for children from class five. Therefore it seems plausible that the supportiveness and teaching style of the teacher are predictive for the individual achievement of children with MD from class eight.

3.7.4. Conclusion. To sum up, attitudes towards the teacher are predictive for individual achievement in the early years, but not in class eight where children of average ability are concerned; however, this finding is reversed for children with $\mathrm{MD}$, as attitudes towards the teacher only seem to have more impact in the later years. This implies that the role of the teacher in individual achievement gradually decreases in children of average ability that have established a positive self-concept and are able to perform at an average level, irrespective of the way in which mathematics is taught. The individual achievement of children with MD, on the other hand, appears to become more closely associated with their responses towards the teacher in the higher grades, presumably due to a lack of self-efficacy. This is related to both repeated episodes of disappointment and the externalisation of attributes for success and failure. It is suggested that the association of these factors is investigated in future studies.

It is possible that because the different samples in this study had a different mathematics teachers, attitudes towards the teacher might be somewhat accounted for by differences in the teachers' personalities rather than due to differences between children with $\mathrm{MD}$ and average ability children from classes five and eight. In future work, a longitudinal study of stability and change in children's affective responses towards one teacher over an extended period of time might be possible. Given that a positive interaction between student and teacher is particularly important for at-risk children, future research might also be required to examine which interventions might help improve children's affective responses towards their mathematics teacher.

3.8. Self-Efficacy. Children of average ability yielded a mean score of 3.92, compared to a mean score of 3.5 yielded by children with MD. A two-between factor ANOVA shows that the main effect of achievement is statistically significant $F_{(1,139)}=12.13, P<.1$. Also, the analysis indicates an interaction effect between achievement and class which is statistically significant $F_{(1,139)}=4.56, P<.05$. Children with $\mathrm{MD}$ from class eight yielded a score of 3.31 , whereas their peers from class five scored 3.7 on average. The finding is reversed in the group of children of average ability.

3.9. Linear Regression. For children of average ability from class five, there was an association between self-efficacy beliefs and mathematics grade (multiple $r=.35$ ). The adjusted value of $r^{2}$ shows that $89 \%$ of the variance in mathematics grades among children of average ability from class five can be explained by the scores on the self-efficacy measure. According to the regression coefficient, the grade improves by .75 as self-efficacy measurement increases by one unit. This finding approached statistical significance
$\left(F_{(1,21)}=3.73, P<.05\right)$. For children with $\mathrm{MD}$ from class five $\left(F_{(1,46)}=.54 ; P=.46\right)$, this association is not significant.

For children of average ability from class eight, there was no association between self-efficacy beliefs and mathematics grade $\left(F_{(1,21)}=.61 ; P=.05\right)$. This is different to the results of children with $\mathrm{MD}$. For children with $\mathrm{MD}$, there is a moderately strong association between self-efficacy beliefs and mathematics grade (multiple $r=.5$ ). It was found that, for every increase on the self-efficacy measure, school report grades in mathematics improve by .82 . The self-efficacy measure accounts for 23\% (adjusted $r^{2}$ ) of the variability in the school report grade for mathematics. The $F$ value $(1,43)=$ 14.08 has an associated probability value of $P<.01$, which shows that this association is significant in the group of children with MD.

3.10. Discussion. A key finding which emerged from the findings is that children with MD from class eight hold significantly lower self-efficacy beliefs than their younger counterparts from class five. Hence, it seems that the selfefficacy beliefs of both younger and older children of average ability are similar, whereas the self-efficacy beliefs of children with MD seem to decline over time. The finding that differences in self-efficacy beliefs between children only emerge in class eight seems to suggest that repeated experiences of satisfactory achievement helps children to maintain a positive judgement of their ability to accomplish their learning goals, whereas repeated experience of difficulties which eventually result in low achievement results in a negative perception of one's capability to attain learning goals. Overall, this finding suggests that self-efficacy is linked to ability, which follows Bandura's argument that personal achievement is an important factor for self-efficacy.

3.10.1. Self-Efficacy in Children from Class Five. An interesting finding was that children with $\mathrm{MD}$ and average ability children from class five expressed similar self-efficacy beliefs. This finding was unanticipated, because the existing literature indicates that low achieving children are typically associated with low self-efficacy beliefs. Such findings have previously been used to support the notion that low achievement precedes low self-efficacy beliefs. The finding that children with $\mathrm{MD}$ and average ability children do not significantly differ in their self-efficacy beliefs seems to contradict this assumption.

To recap, children were tracked on different secondary school types after four years of primary school, depending on their math ability in primary school. Thus, children with MD had already experienced frustration and low achievement in primary school before they were tracked with peers of the same ability in class five. Despite these experiences, children with MD did not exhibit significantly lower self-efficacy beliefs than their average achieving peers. This implies that ability itself constitutes a mediating factor rather than a causal factor for self-efficacy. Indeed, the results of a linear regression analysis showed that differences in self-efficacy beliefs were not predictive for ability differences between children with MD and average ability children. Therefore, 
the absence of differences in self-efficacy beliefs between children with MD and average ability children from class five corresponds to Schunk's [38] assertion that "although selfefficacy is influenced by prior accomplishments it is not a mere reflection of them."

3.10.2. Self-Efficacy Beliefs in Children from Class Eight. Whereas children with MD and average ability children do not differ in their self-efficacy beliefs, there are significant disparities between reported self-efficacy beliefs in class eight. The findings show that children with MD express lower self-efficacy beliefs than their average achieving peers. Also, differences in self-efficacy were found to be a significant predictor for achievement differences among children from class eight with MD, but not for children of average ability.

However, if previous achievement is a determinant of self-efficacy, it could be argued that, by class eight, children with MD and average ability children have had positive as well as negative results with respect to their achievements. In both groups, there are children who perform below average and children who perform above average. Therefore, it may be the case that there should be no difference between the mean self-efficacy belief scores of children with MD and average ability children in class eight. As will be discussed below, Pajares [39] provide a possible resolution to this.

3.10.3. Conclusion. To sum up, children with $\mathrm{MD}$ and average ability children do not differ significantly in their self-efficacy beliefs in their first year of secondary school. This seems to change over time, in that self-efficacy beliefs in children with MD seem to decrease between class five and class eight, whereas no differences were observed between children of average ability from classes five and eight. Thus, even if children from both groups are likely to have experienced failure at some point up to class eight, children of average ability from class eight displayed significantly more positive self-efficacy beliefs than children with MD. Therefore, the present results allow the tentative conclusion that low achievement in itself is not the source of low selfefficacy beliefs. This findings corroborate previous results, which show that self-efficacy beliefs go beyond a reflection of past achievement, and that the inferential process by which people derive those beliefs is based, not only on personal factors, but also on situational factors such as the social context which provides a reference framework for individual achievement (Bandura \& Schunk [40]).

Attendance at general secondary school is a synonym for low achievement and academic and behavioural difficulties (Kauffman, 1997) which might give rise to negative selflabelling processes. Being classified as children with MD is likely to be detrimental for children's perceived ability and might also decrease the effort that children devote to learning. Thus, it is safe to assume that children with MD generally foster more negative collective self-efficacy beliefs. In line with the literature discussed above, it seems plausible that the corrosion of self-efficacy in children with MD might be due to an interaction between environmental/situational efficacy appraisals, perceived collective efficacy, and attribution style, which comprises perceived achievement and outcome expectations.

A possible extension to the present study would be to include items targeted towards collective efficacy. As has been discussed above, the interaction effect between perceived collective efficacy and situational/environmental responses towards children's achievement is an important source for efficacy expectations and future research on self-efficacy might therefore be more cognisant of this factor. In addition, future research might address the relationship between collective efficacy, situational/environmental experiences, and causal ascriptions by investigating children's beliefs about the origins of their mathematical difficulties. Future research on of the effects of low self-efficacy would be important to provide interventions which might help to modify children's efficacy expectations.

3.11. Learning Environment. Children with MD had a mean score of 2.8, whereas children of average ability had a mean score of 3.94. Thus, the low scores of the children with MD suggest that they reported more classroom disturbances than their average ability peers. The results of the two-between factor ANOVA show that the main effect of achievement is statistically significant, $F_{(1,139)}=99.05, P<.01$.

3.12. Linear Regression. For children of average ability from class five there was a moderate association between perceived learning environment and mathematics grade (multiple $r=$ .40). The adjusted value of $r^{2}$ shows that affective responses towards the classroom environment are the source of $13 \%$ of the variance in mathematics grades among children of average ability from class five. The regression coefficient indicates that, if perceived learning environment measurement increases by one unit, then the grade improves by .77. This finding approached statistical significance $\left(F_{(1,27)}=5.24\right.$, $P<.05)$. There is also an association for children with MD between perceived learning environment and mathematics grade (multiple $r=.29$ ). The adjusted value of $r^{2}$ shows that $6 \%$ of the variance in mathematics grades of children with $\mathrm{MD}$ from class five is due to their affective responses towards the classroom environment.

For children of average ability from class five, there was no association between affective responses towards the classroom environment and mathematics grade $\left(F_{(1,21)}=\right.$ $.61 ; P=.44)$. This is different to the results of children with MD from class eight. For children with MD, there is a moderately strong association between affective responses towards the classroom environment and mathematics grade (multiple $r=.38$ ). It was found that, for every increase on the perceived learning environment scale, school report grades in mathematics improve by .81. Perceived learning environment accounts for 12\% (adjusted $r^{2}$ ) of the variability in school report grade for mathematics. The $F$ value $(1,43)=$ 7.02 has an associated probability value of $P<.01$, which shows that this association is significant in the group of children with MD. 
3.13. Discussion. In contrast to previous studies which were concerned with children's perception of more general aspects of the classroom environment (cf. Goh and Fraser [8]), the present study was specifically focussed on perceived learning environment as a specific domain of the classroom environment. The "learning environment" subscale referred to the perceived behavioural conduct of children during mathematics lessons. The subscale specified perceptions rather than attitudes because attitudes towards a certain object typically involve a favourable or unfavourable evaluation, whereas perceptions and beliefs merely represent an individual's information about the object (Fishbein \& Azjen [31]). The conceptual distinction between perceptions and attitudes is crucial because children who perceive their classroom environment as noisy and turbulent might not necessarily have a negative attitude towards misconduct.

Overall, the findings show that children with MD who are more likely to perceive their classroom are subject to disturbances and misconduct more than children of average ability. While the literature on differences between children with MD and average ability children with respect to their perceived learning environment is not extensive, the present finding is consistent with other studies which showed that low achieving children tend to be associated with behavioural peculiarities, classroom disturbances, and generally troubled classroom environments (Rösner [41]). This supports Kauffman's (1997) argument that "low achievement and behaviour problems go hand in hand." The absence of any interaction effects between the affective responses, ability and class suggests that the classroom environment remains relatively stable as children proceed across secondary school years. However, the results of a linear regression analysis indicate that the amount of variance in individual achievement which can be attributed to children's perception of the classroom conduct varies across groups.

\subsubsection{Perception of Learning Environment in Children from} Class Five. The results of a linear regression analysis show that the individual achievement of class five children from both groups is related to their perception of classroom conduct. This finding is consistent with previous research, which showed that the classroom environment is a particularly important variable for younger children. A somewhat unexpected finding was that perceptions of classroom conduct are more predictive for individual achievement of children of average ability than for children with MD from class five. In contrast to the present finding, Fraser [42] found that the association between individual achievement and perceived learning environment is stronger for problematic children. Given that children with MD perceived more classroom disturbances than children of average ability, it was anticipated that the association is stronger for these children. However, the finding of the study does not support this view.

One possible explanation is that children with $\mathrm{MD}$ are less receptive of classroom disturbances. Because problematic behaviour and misconduct are generally common among secondary school children, it is likely that children with MD are no longer distracted by cases of misconduct. It is possible that children with MD became habituated to learning in a turbulent classroom environment to an extent that incidences of misconduct are no longer consciously processed and do not require attentional resources. In other words, the association between children's individual achievement and their affective responses might be less pronounced in children who are used to a disquiet and a problematic classroom environment, whereas children of average ability might be used to a generally quiet classroom environment and are more affected by cases of misconduct of their peers.

Such an explanation is comparable to the "big fish, little pond" frame-of-reference theory of social comparisons proposed by Marsh [10]. In its original formulation, the theory predicts that the same objective academic outcomes can elicit different responses from children in different learning environments. An average grade of three, for example, might satisfy a child with MD, where the average achievement is generally low; however, for an average ability child, a grade of three is disappointing compared to the average achievement of his/her peers. This theory can be applied to the present findings; in an otherwise quiet and disciplined classroom of children of average ability, minor incidences might cause distraction, occupy children's attentional resources, and affect their learning process. Thus, it is difficult to compare the association between perceived learning environment disturbances and individual achievement if the role of frames of reference is ignored.

3.13.2. Developmental Trajectories of Perceived Learning Environment. One key finding was that perceived learning environment did not significantly differ between children from classes five and eight, neither among children with MD nor among children of average ability. It was anticipated that, at the start of adolescence, children in class eight in both groups would report more classroom disturbances. Children of this age, thirteen to fifteen, are typically assumed to be less conforming in the classroom and it was supposed that this affects the perception of their classroom environment. However, the results challenge this assumption. One potential explanation for these results is that while classroom conduct might actually decrease compared to that of class five, children in class eight might become habituated to their classroom environment. Indeed, perception does not arise within a social vacuum and children's perception of their classroom conduct might be biased because they are themselves part of their classroom environment.

\subsubsection{Perceived Learning Environment and Achievement. To summarise, the individual achievement of class five children with MD and average ability children was found to be associated with their perceptions of classroom conduct. This pattern of findings is different for children from class eight; the results of the linear regression analysis indicate that differences in perceived learning environment conduct are only predictive for individual achievement differences where children from class eight are concerned. One explanation for}


this finding is that, in contrast to their younger peers from class five, classroom disturbances and discipline problems among children of average ability in class eight are minimised to such an extent that they have virtually no association with the learning processes and individual achievement. This hypothesis can be supported by the finding that children of average ability from class eight perceive the classroom to be less disruptive than children with MD. Children with $\mathrm{MD}$, on the other hand, seem to be exposed to a more difficult classroom environment and the results show that the perception of classroom difficulties is predictive for individual differences in achievement. Taken together, these findings are in conjunction with the findings of Goodenow [43] and Hymel et al. [44], who found that children's perception of the classroom is an important predictor for academic achievement.

The association between children's perceptions of the classroom environment and achievement can be explained with reference to social cognitive concepts such as selfefficacy (Bandura [11]). In essence, advocates of such an approach to classroom problems assume that "perceptions of the classroom influence students' beliefs about themselves... and these beliefs, in turn, influence the nature and extent of their engagement in academic tasks" (Patrick et al. [45]). Indeed, there is evidence that problematic classroom behaviour is indicative for children who are not able to follow the pace of instruction (Lopes, 2002), and it could be argued that children with learning difficulties are more likely to engage in misconduct because it distracts them from their academic limitations and helps them gain attention from their peers and the teacher.

Trivial as it seems, being the centre of attention in the eyes of their teacher and peers might actually provide a source of self-worth to otherwise low achieving children. Classroom misconduct might therefore constitute an avoidance behaviour which helps children to protect their selfconcept in the light of repeated experiences of learning difficulties and frustration. The present findings support the view that low achievement and classroom misbehaviour are factors which reinforce each other and lead to a vicious circle. In order to investigate the hypothesis that classroom disturbances are related to low levels of self-worth, it is important to discuss the present findings in relation to the results of the self-efficacy measure.

Another factor which might contribute to this vicious circle is the behaviour of the teacher. Teachers of low achieving children are likely to face more challenges and academic and behavioural difficulties than teachers of average achieving children, and this might lead them to respond more aggressively and to adopt tactics such as screaming, yelling, and corporal punishment to manage the classroom. However, there is evidence that these tactics do not alleviate but increase incidences of misbehaviour (Lewis [46]). In addition, children might engage in misbehaviour if they believe that they are unfairly treated by the teacher, that they receive insufficient support or if they are dissatisfied with the teaching style. Therefore, it is crucial to discuss the present results in relation to the findings of the "affective responses towards the teacher" subscale.
3.13.4. Conclusion. It is important to note that the crosssectional nature of the data does not permit causal relationships to be inferred. Also, the association between perceived learning environment and the individual was investigated in the mathematics classroom only, and it may be important to examine this association in other academic subjects. An investigation into how perceived learning environment relates to other aspects of the classroom environment such as perceived quality of peer relationships, perceived competitiveness, and an integration of teachers' perception of the classroom constitute topics for further research. Consequently, the direction of the relationship between low achievement, self-belief, and behavioural problems in the classroom environment is not clear. It seems plausible that there is a reciprocal relationship between these factors and occurrence of one of these variables constitutes a "risk factor" which might trigger the occurrence of the other factor. Therefore, it is essential to triangulate the present results within the context of the findings of self-efficacy and the attitudes towards the teacher scales.

\section{Overall Discussion and Conclusion}

The current study aimed to investigate differences in affective responses towards mathematics between children with $\mathrm{MD}$ and children of average ability, and to examine the association between affective responses and mathematical achievement, as determined by school grades. To recap, children with MD attend general secondary schools which make the lowest academic demands compared to other secondary school types in Germany and have a predominantly vocational orientation. Taken together, the present results suggest that children with MD tend to express more negative affective responses towards different aspects of mathematics than children of average ability. However, it seems that children with MD and average ability children differ with respect to stability and change in their affective responses. Apart from the results of the perceived learning environment scale, the affective responses of children with MD seem to decline between class five and class eight, whereas the affective responses of children of average ability from classes five and eight are similar. This implies that, in contrast to children with MD, the affective responses of children of average ability seem to be less affected by variances and remain stable. This is an unexpected finding, given that children from class eight are assumed to respond differently to their environment and experiences than children from class five. Indeed, it was predicted that children with MD and average ability children should express a decline in selfefficacy, because it could be assumed that at the start of adolescence, children in class eight are more critical in their self-judgements.

However, the results of the current study show that this is not the case for children of average ability. It has been argued that even children of average ability experience frustration and distress over the years. Nevertheless, the results indicate that children of average ability have different mechanisms to deal with negative experiences which enable them to 
maintain positive affective responses over time. In other words, it seems that children of average ability are able to balance out personal or interpersonal difficulties over the years, which results in stability in their affective responses. The assumption that children of average ability are less influenced by affective factors than children with $\mathrm{MD}$ is supported by the results of the multiple regression analysis: while affective responses predicted achievement differences in children with MD, this was not the case for children of average ability.

In order to provide a more general explanatory framework for the present results, it has been proposed that the differences in stability and change of affective responses between children with MD and average ability children between classes five and eight might be explained by a latent variable, namely, collective self-efficacy. According to Bandura [11], collective self-efficacy is concerned with the performance capability of a social system as a whole. Based on the present results, it has been suggested that collective efficacy constitutes a latent variable which mediates the affective responses of children with MD and average ability children as well as the association between differences in affective responses and individual differences in achievement. However, it seems that children's perception of their collective social efficacy gradually develops as they progress through secondary school. Indeed, the present results show that there is no difference in self-efficacy belief between children with MD and average ability children, despite the fact that children with MD in class five already have a history of frustrating experiences and low achievement in primary school.

This finding substantiates the argument that differences in children's self-judgements might not be due to individual low achievement as such, but are mediated by the experience of being exposed in a certain social system. Schools which are segregated with respect to ability and are exclusively populated by children with academic difficulties and low achievement might constitute a social system which is not beneficial for children's collective self-efficacy. It has been argued that negative collective self-efficacy beliefs are accompanied by withdrawal and negative self-labelling processes, which can occupy limited processing resources and therefore might constitute an impediment to cognitive processes. To sum up, collective efficacy seems to be an important variable where children's affective responses and their relationship to individual achievement are concerned. Overall, the results tentatively indicate that, while anxiety and attitudes towards the teacher constitute risk factors which are reciprocally related, their relative impact and their association with individual achievement is mediated by collective efficacy. Future research would be required to specify the role of collective efficacy, a construct which has so far only resided at the periphery of research on affective responses (Bandura [11]).

\section{References}

[1] L. H. Reyes, "Affective variables and mathematics education," The Elementary School Journal, vol. 84, no. 5, pp. 558-581, 1984.
[2] M. H. Ashcraft and E. P. Kirk, "The relationships among working memory, math anxiety, and performance," Journal of Experimental Psychology: General, vol. 130, no. 2, pp. 224-237, 2001.

[3] X. Ma and J. Xu, "The causal ordering of mathematics anxiety and mathematics achievement: a longitudinal panel analysis," Journal of Adolescence, vol. 27, no. 2, pp. 165-179, 2004.

[4] J. S. Kellogg, D. R. Hopko, and M. H. Ashcraft, "The effects of time pressure on arithmetic performance," Journal of Anxiety Disorders, vol. 13, no. 6, pp. 591-600, 1999.

[5] P. Grootenboer and B. Hemmings, "Mathematics performance and the role played by affective and background factors," Mathematics Education Research Journal, vol. 19, no. 3, pp. 320, 2007.

[6] O. Rubinsten and R. Tannock, "Mathematics anxiety in children with developmental dyscalculia," Behavioral and Brain Functions, vol. 6, article 46, 2010.

[7] B. Hemmings, P. Grootenboer, and R. Kay, "Predicting mathematics achievement: the influence of prior achievement and attitudes," International Journal of Science and Mathematics Education. In press.

[8] S. C. Goh and B. J. Fraser, "Teacher interpersonal behaviour, classroom environment and student outcomes in primary mathematics in Singapore instruments," in International Handbook of Science Education, B. J. Fraser and K. G. Tobins, Eds., Kluwer Academic Publishers, London, UK, 1998.

[9] K. R. Wentzel, "Social support and adjustment in middle school: the role of parents, teachers, and peers," Journal of Educational Psychology, vol. 90, pp. 202-209, 1998.

[10] H. W. Marsh, "The Big-Fish-Little-Pond effect on academic self concept," Journal of Educational Psychology, vol. 79, no. 3, pp. 280-295, 1987.

[11] A. Bandura, Self-Efficacy: The Exercise of Control, Freeman, New York, NY, USA, 1997.

[12] H. W. Marsh and R. Craven, "Academic self-concept: beyond the dustbowl," in Handbook of Classroom Assessment, G. D. Phye, Ed., Academic Press, San Diego, Calif, USA, 1997.

[13] M.-S. Chiu and D. Whitebread, "Taiwanese teachers' implementation of a new 'constructivist mathematics curriculum': how cognitive and affective issues are addressed," International Journal of Educational Development. In press.

[14] A. Wigfield and J. L. Meece, "Math anxiety in elementary and secondary school students," Journal of Educational Psychology, vol. 80, no. 2, pp. 210-216, 1988.

[15] A. Bandura, "Self-efficacy mechanism in human agency," American Psychologist, vol. 37, no. 2, pp. 122-147, 1982.

[16] N. E. Betz and G. Hackett, "The relationship of mathematics self-efficacy expectations to the selection of science-based college majors," Journal of Vocational Behavior, vol. 23, no. 3, pp. 329-345, 1983.

[17] F. Pajares and J. Kranzler, "Self-efficacy beliefs and general mental ability in mathematical problem-solving," Contemporary Educational Psychology, vol. 20, no. 4, pp. 426-443, 1995.

[18] F. Pajares and M. D. Miller, "Role of self-efficacy and selfconcept beliefs in mathematical problem solving: a path analysis," Journal of Educational Psychology, vol. 86, no. 2, pp. 193-203, 1994.

[19] X. Ma, "A meta-analysis of the relationship between anxiety toward mathematics and achievement in mathematics," Journal for Research in Mathematics Education, vol. 30, no. 5, pp. 520-540, 1999.

[20] R. Hembree, "The nature, effects, and relief of mathematics anxiety," Journal for Research in Mathematics Education, vol. 21, pp. 33-46, 1990. 
[21] K. Newstead, "Aspects of children's mathematics anxiety," Educational Studies in Mathematics, vol. 36, no. 1, pp. 53-71, 1998.

[22] T. B. Murdock and A. Miller, "Teachers as sources of middle school students' motivational identity: variable-centered and person-centered analytic approaches," Elementary School Journal, vol. 103, no. 4, pp. 383-399, 2003.

[23] C. Midgley, H. Feldlaufer, and J. S. Eccles, "Change in teacher efficacy and student self- and task-related beliefs in mathematics during the transition to junior high school," Journal of Educational Psychology, vol. 81, no. 2, pp. 247-258, 1989.

[24] L. Steinberg, Beyond the Classroom: Why School Reform has Failed and What Parents Need to Do, Simon \& Schuster, New York, NY, USA, 1996.

[25] J. M. Barth, S. T. Dunlap, H. Dane, J. E. Lochman, and K. C. Wells, "Classroom environment influences on aggression, peer relations, and academic focus," Journal of School Psychology, vol. 42, no. 2, pp. 115-133, 2004.

[26] K. M. Loewenthal, An Introduction to Psychological Tests and Scales, Psychology Press, Hove, UK, 2nd edition, 2001.

[27] S. Tobias, "Math anxiety and physics: the problem of teaching 'difficult' subjects," Physics Today, vol. 38, no. 6, pp. 61-68, 1985.

[28] S. Dossel, "Maths anxiety," Australian Mathematics Teacher, vol. 49, no. 1, pp. 4-8, 1993.

[29] G. E. Hunt, "Math anxiety-where do we go from here?" Focus on Learning Problems in Mathematics, vol. 7, pp. 29-40, 1985.

[30] E. H. Fennema and J. A. Sherman, "Sex-related differences in mathematics achievement and related factors: a further study," Journal for Research in Mathematics Education, vol. 7, pp. 189203, 1978.

[31] M. Fishbein and I. Ajzen, Belief, Attitude, Intention, and Behavior: An Introduction to Theory and Research, AddisonWesley, Reading, Mass, USA, 1975.

[32] E. H. Kroesbergen, J. E. H. Van Luit, and C. J. M. Maas, "Effectiveness of explicit and constructivist mathematics instruction for low-achieving students in the Netherlands," Elementary School Journal, vol. 104, no. 3, pp. 233-251, 2004.

[33] R. E. Mayer, "Should there be a three-strikes rule against pure discovery learning? The case for guided methods of instruction," American Psychologist, vol. 59, no. 1, pp. 14-19, 2004.

[34] A. Bandura, Social Foundations of Thought and Action: A Social Cognitive Theory, Prentice-Hall, Englewood Cliffs, NJ, USA, 1986.

[35] D. Carnine, "Instructional design in mathematics for students with learning disabilities," Journal of Learning Disabilities, vol. 30, no. 2, pp. 130-141, 1997.

[36] P. A. Kirschner, J. Sweller, and R. E. Clark, "Why minimal guidance during instruction does not work: an analysis of the failure of constructivist, discovery, problem-based, experiential, and inquiry-based teaching," Educational Psychologist, vol. 41, no. 2, pp. 75-86, 2006.

[37] M. Lebens, The cognitive and affective dimensions of mathematical difficulties in schoolchildren, Ph.D. thesis, University of Glamorgan, 2008.

[38] D. H. Schunk, "Effects of effort attributional feedback on children's perceived self-efficacy and achievement," Journal of Educational Psychology, vol. 74, no. 4, pp. 548-556, 1982.

[39] F. Pajares, "Current directions in self-efficacy research," in Advances in Motivation and Achievement, M. Maehr and P. R. Pintrich, Eds., JAI Press, Greenwich, Conn, USA, 1997.
[40] A. Bandura and D. H. Schunk, "Cultivating competence, self-efficacy, and intrinsic interest through proximal selfmotivation," Journal of Personality and Social Psychology, vol. 41, no. 3, pp. 586-598, 1981.

[41] E. Rösner, "Die sogenannte Durchlässigkeit," Neue Deutsche Schule, vol. 6, no. 7, pp. 14-18, 1997.

[42] B. J. Fraser, Classroom Environment, Croom Helm, London, UK, 1986.

[43] C. Goodenow, "Strengthening the links between educational psychology and the study of social contexts," Educational Psychologist, vol. 27, pp. 177-196, 1992.

[44] S. Hymel, C. Comfort, K. Schonert-Reichel, and P. McDougall, "Academic failure and school dropout: the influence on peers," in Social Motivation: Understanding Children's School Adjustment, J. Juvonen and K. R. Wentzel, Eds., Cambridge University Press, New York, NY, USA, 1996.

[45] H. Patrick, A. M. Ryan, and A. Kaplan, "Early adolescents' perceptions of the classroom social environment, motivational beliefs, and engagement," Journal of Educational Psychology, vol. 99, no. 1, pp. 83-98, 2007.

[46] K. G. Lewis, "Using midsemester student feedback and responding to it," New Directions for Teaching and Learning, vol. 87, pp. 33-44, 2001. 


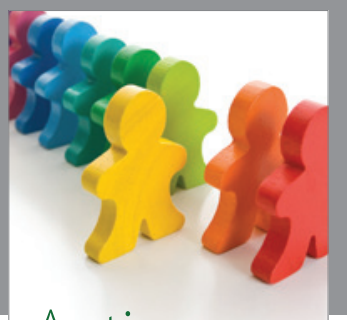

Autism

Research and Treatment
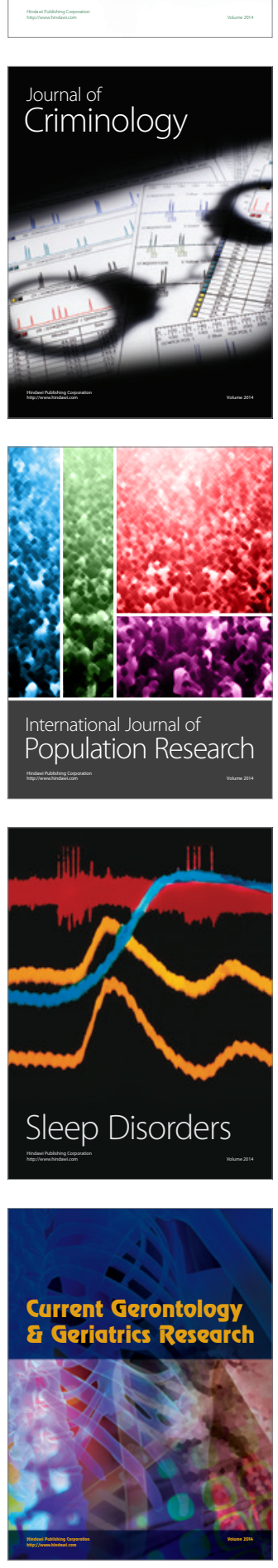
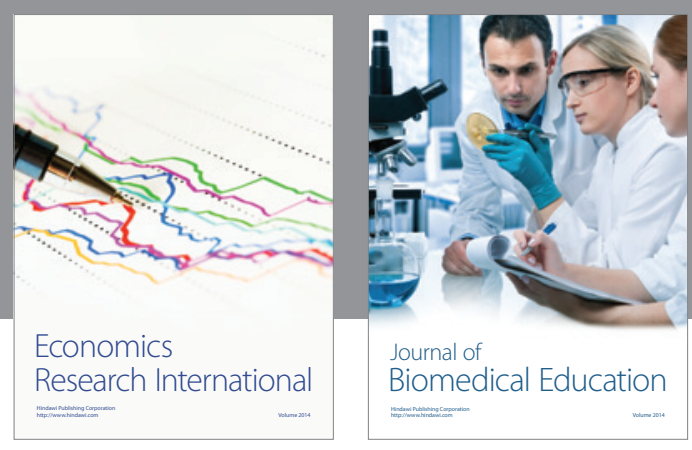

Journal of

Biomedical Education

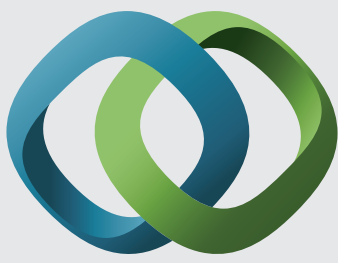

\section{Hindawi}

Submit your manuscripts at

http://www.hindawi.com
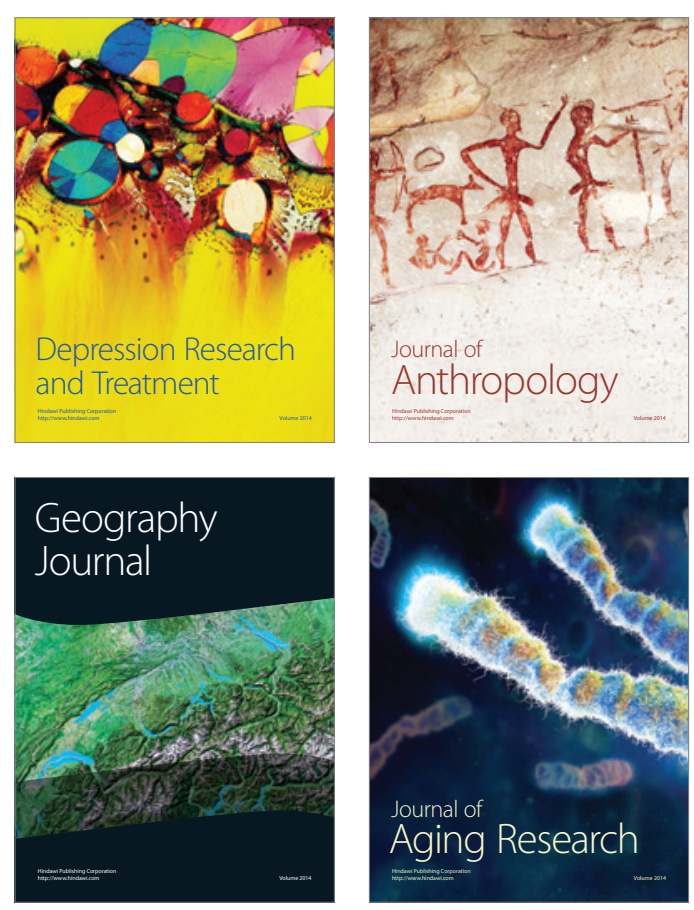

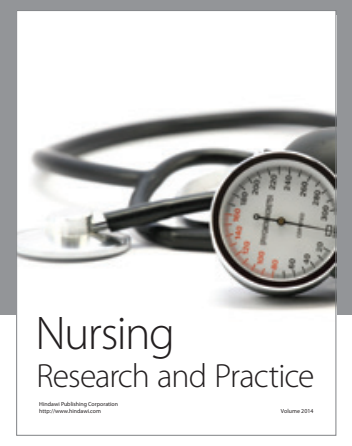

Nursing

Research and Practice

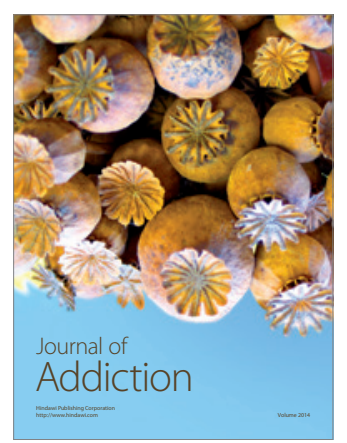

Child Development

Research

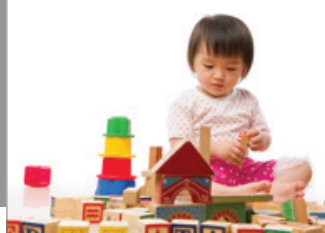

迥
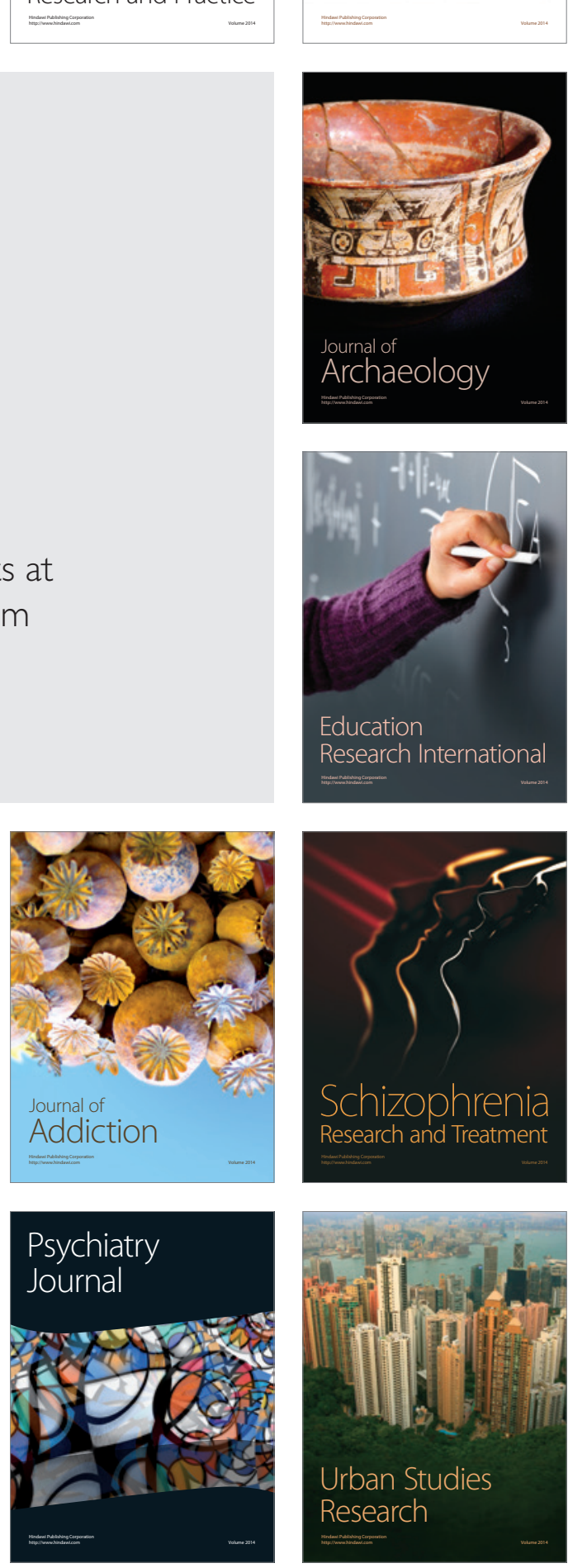